\title{
Langley Mobile Ozone Lidar (LMOL)results from the Denver, CO DISCOVER-AQ campaign
}

\author{
Russell De Young \\ Science Directorate \\ NASA Langley Research Center \\ Hampton, VA 23681 \\ Russell.j.deyoung@nasa.gov
}

William Carrion

Coherent Applications Inc.

Hampton, VA 23681

Denis Pliutau

Science Systems and Applications Inc.

Hampton, VA 23681 


\section{Counties With Monitors Projected to Violate Primary 8-hour Ground-Level Ozone Standards in 2020}

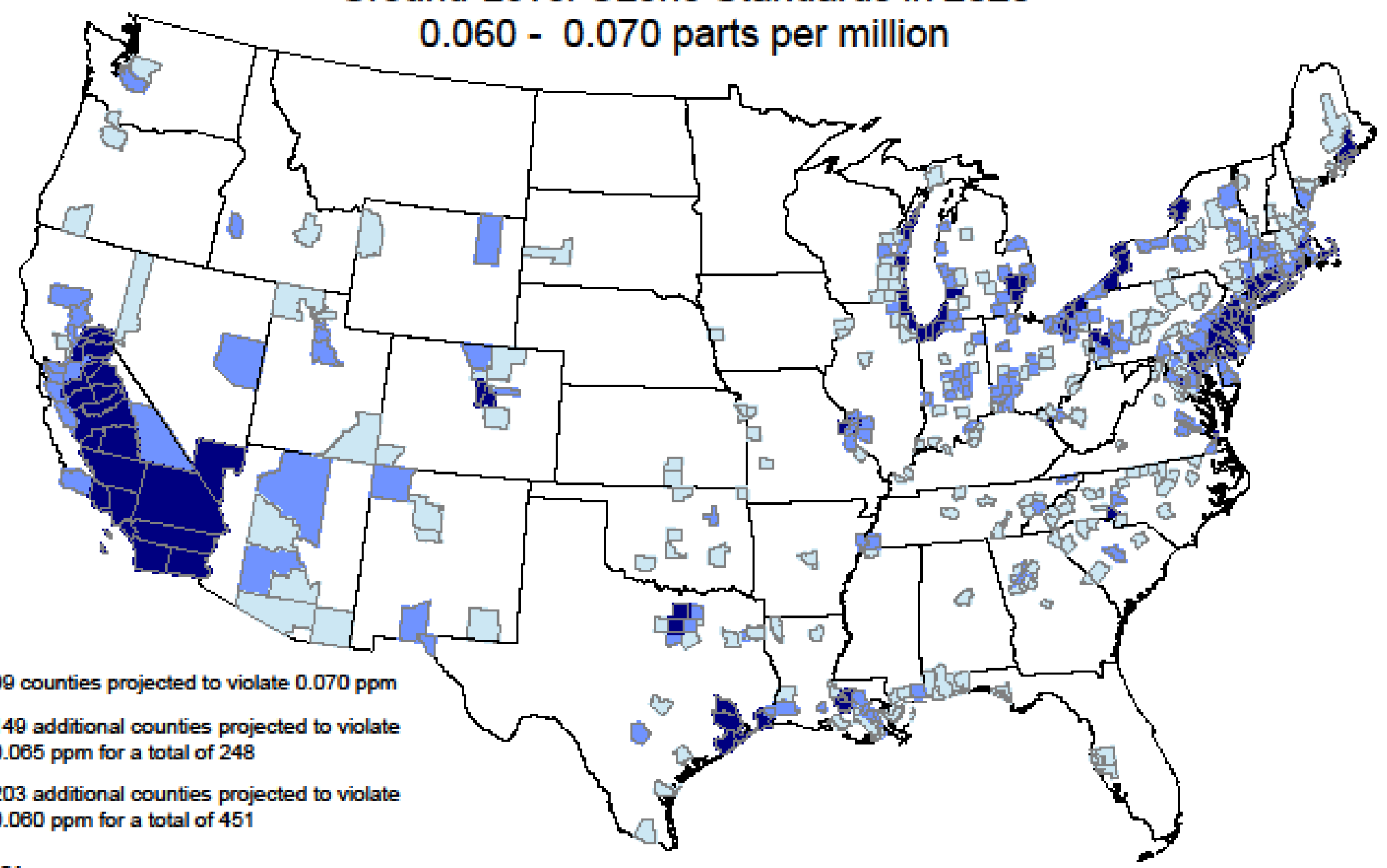

\section{Notes:}

1. The modeled emissions in 2020 reflect the expected emissions reductions from federal programs by 2020 including: the Clean Air Interstate Rule, the Clean Air Mercury Rule, the Clean Air Visibility Rule, the Clean Air Nonroad Diesel Rule, the Light-Duty Vehicle Tier 2 Rule, the Heavy Duty Diesel Rule, the proposed rules for Locomotive and Marine Vessels and for Small Spark-Ignition Engines, and an estimate of State-level mobile and stationary source controls that were projected to be needed to attain pre-existing PM 2.5 and ozone standards.

2. Controls applied are illustrative. States may choose to apply different control strategies for implementation.

3. EPA did not model future violations outside the continental U.S.

4. EPA is proposing to determine compliance with a revised primary ozone standard by rounding the 3-year average to three decimal places. 


\section{Langley Mobile Ozone Lidar is part of the Tropospheric Ozone Lidar Network (TOLNet)}

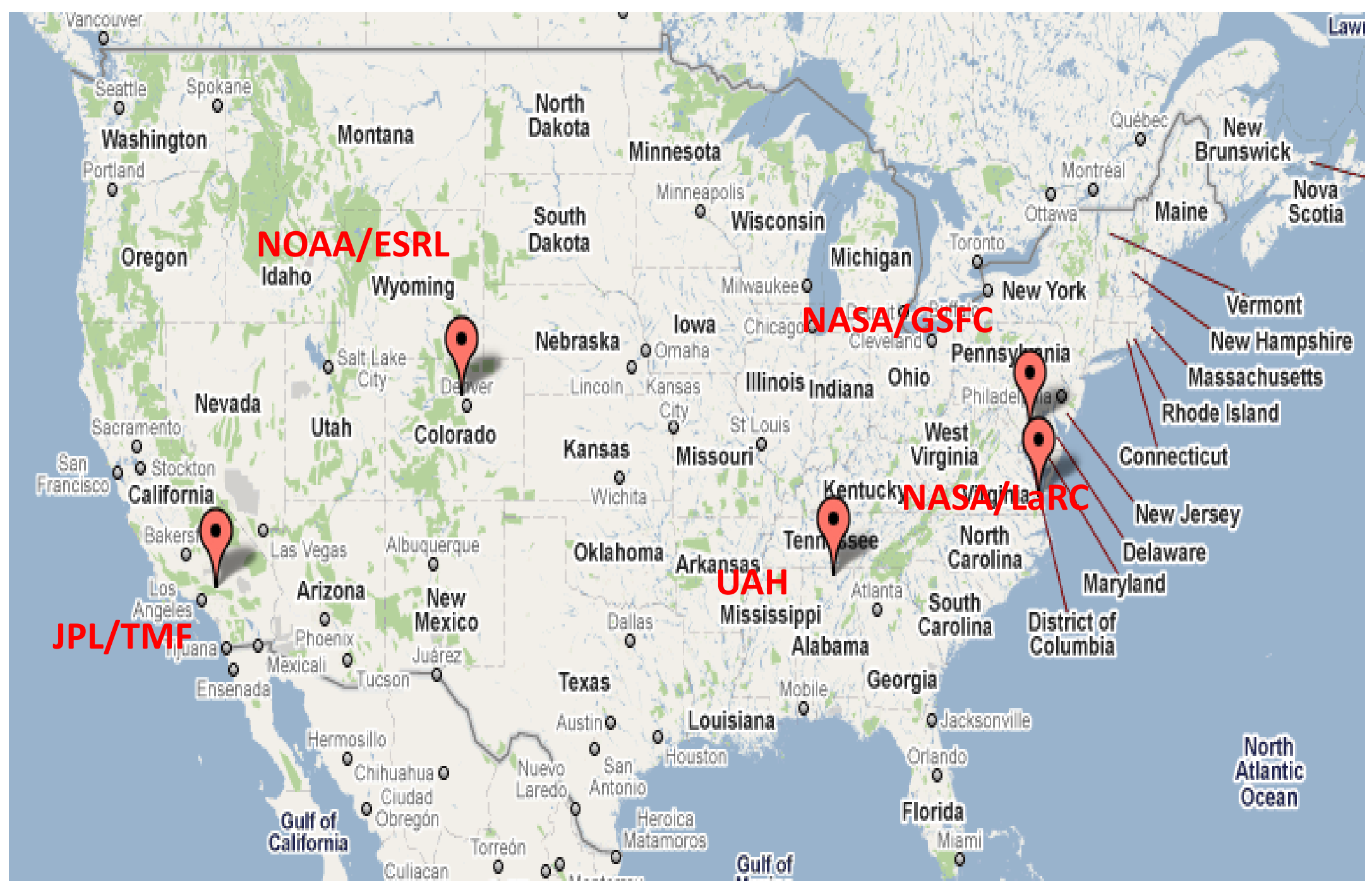




\section{Langley Mobile Ozone Lidar (LMOL) Schematic}

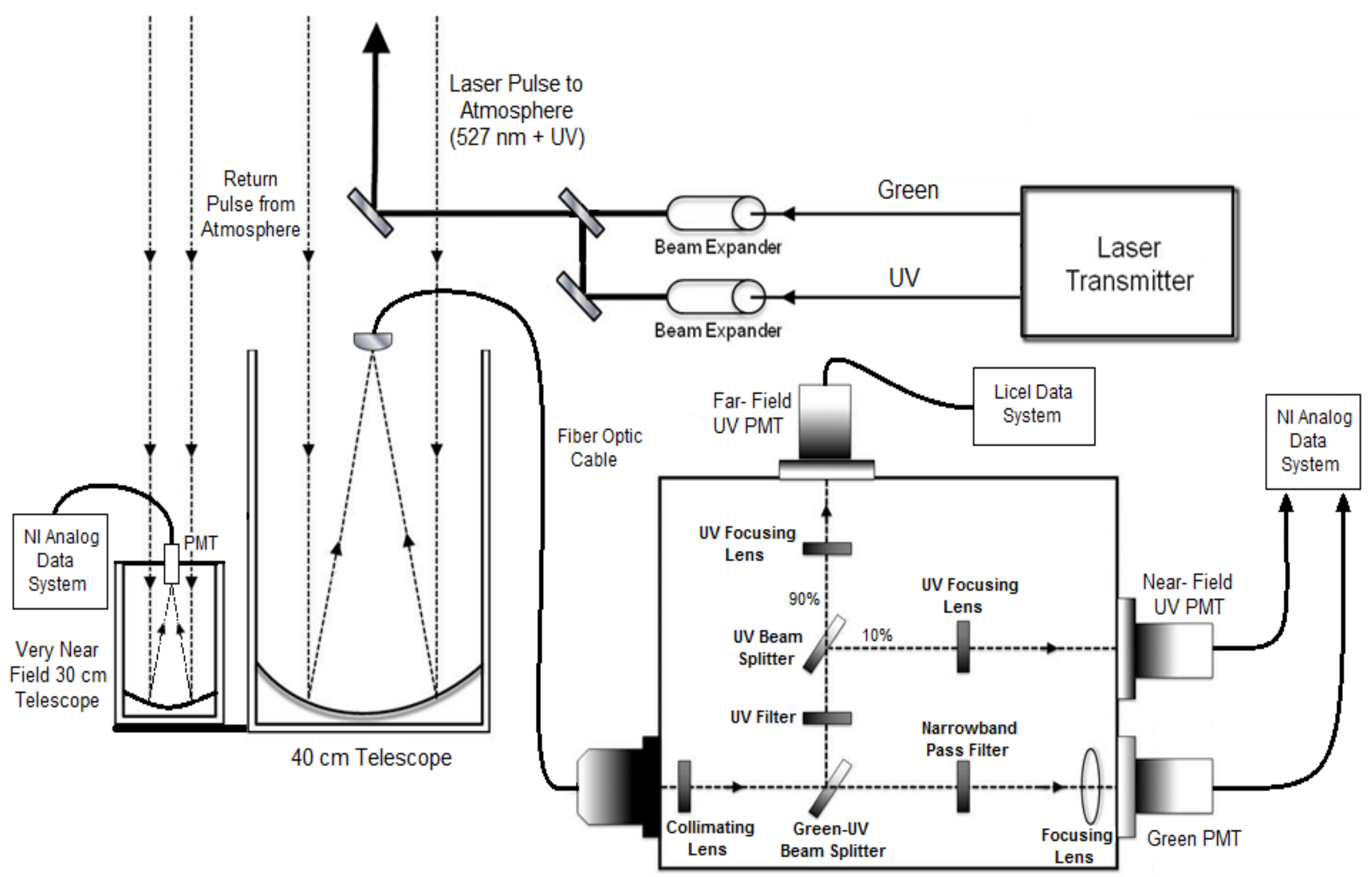




\section{DISCVOVER-AQ Campaign Denver, CO July-August 2014}

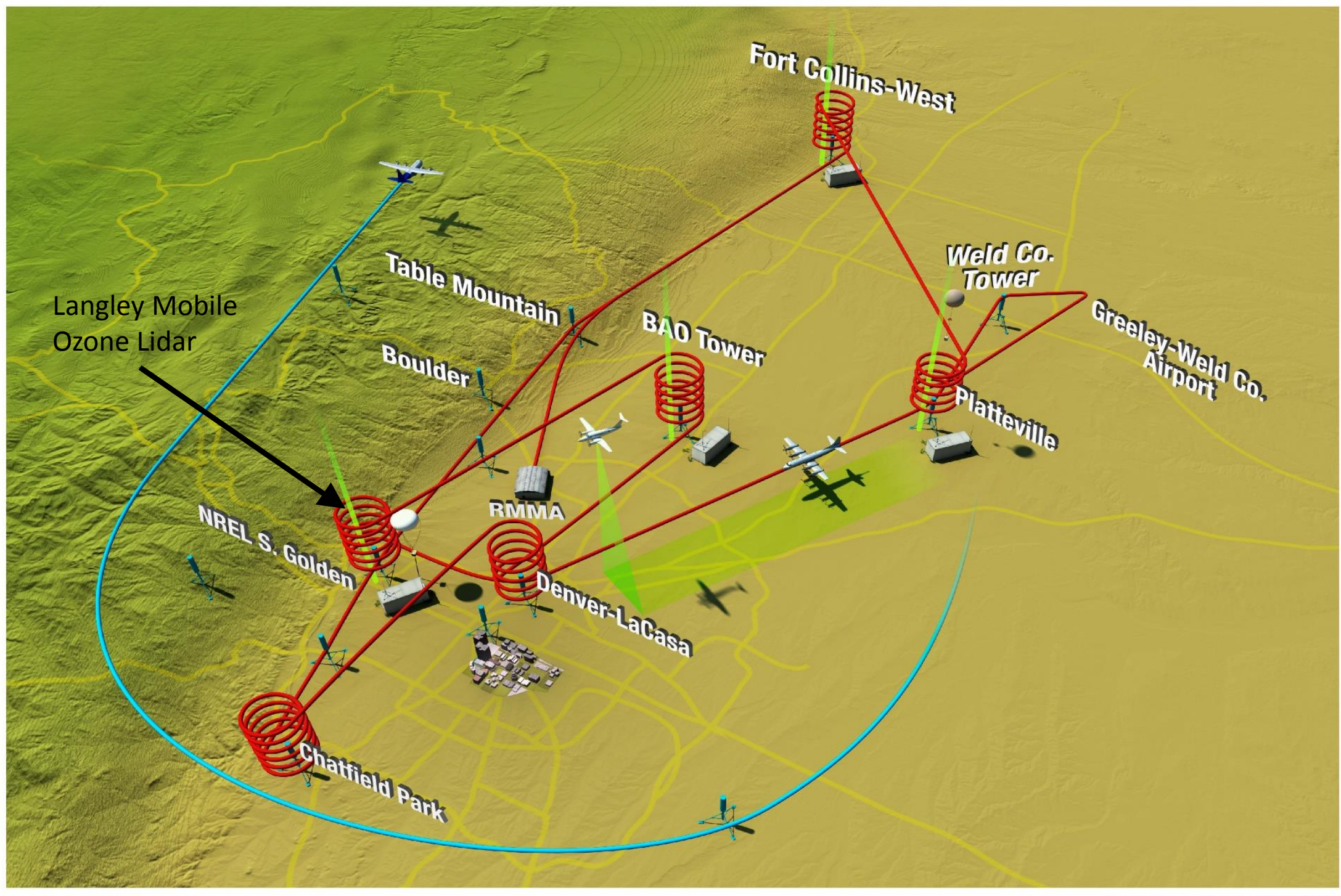




\section{DISCOVER-AQ Goals}

- Relate column observations to surface conditions for aerosols and key trace gases $\mathrm{O} 3, \mathrm{NO} 2$, and $\mathrm{CH} 2 \mathrm{O}$. How well do column and surface observations correlate? What additional variables (e.g., boundary layer depth, humidity, surface type) appear to influence these correlations?

- Characterize differences in diurnal variation of surface and column observations for key trace gases and aerosols. How do emissions, boundary layer mixing, synoptic transport, and chemistry interact to affect these differences?

- Examine horizontal scales of variability affecting future satellites measurements and model calculations. How do different meteorological and chemical conditions cause variation in the spatial scales for urban plumes? 


\section{Langley Mobile Ozone Lidar Trailer}
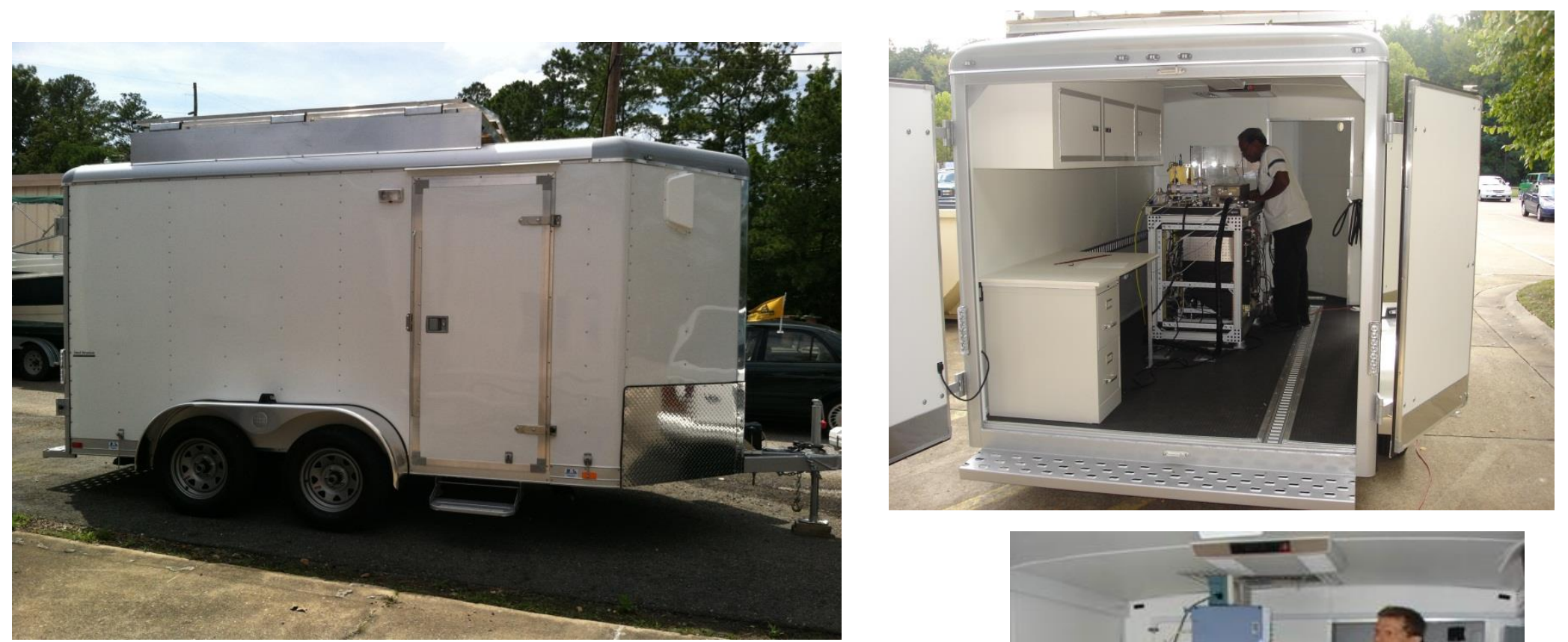

- The system has been configured to enable mobile operation from an environmentally controlled trailer.

- This mobility allows lidar to be set up at remote sites to support major air quality field campaigns.

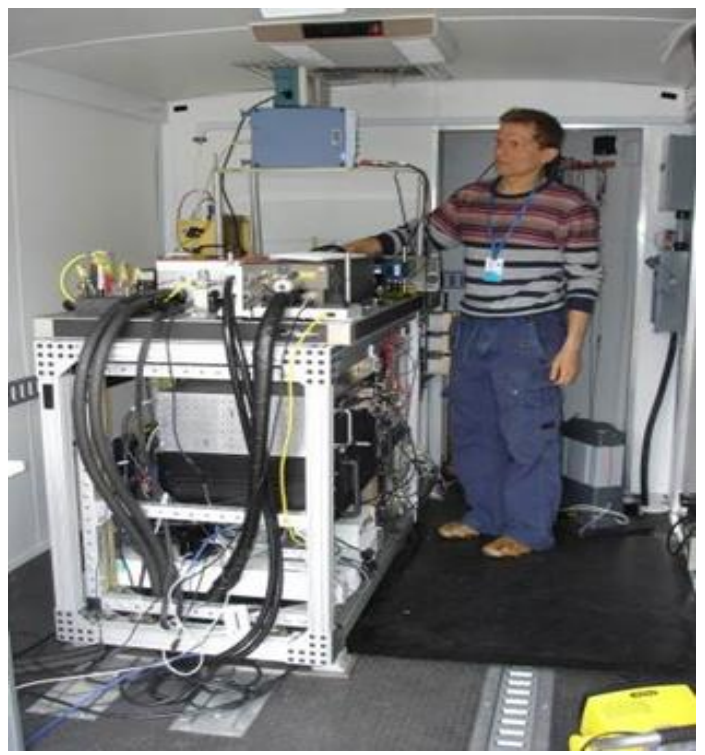


Weekly Ozonesonde Launches Used to Validate Ozone Lidar

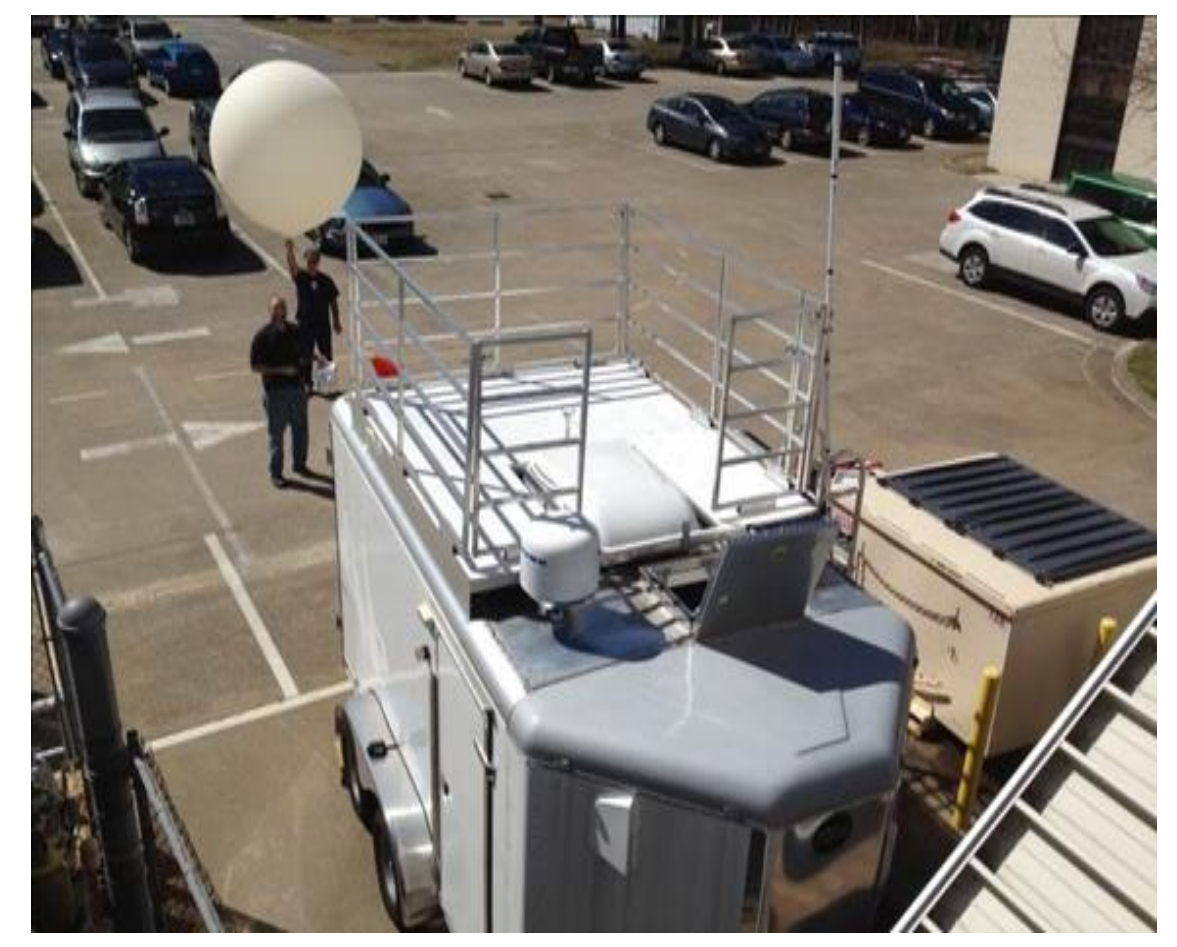




\section{Ground, Ozonesonde and Lidar Ozone Profile January 31, 2014 at LaRC}

Merge of 3 channels (very near field at $36 \mathrm{~m}$ resolution up to 900 meters, near field analog at $90 \mathrm{~m}$ resolution from 900 to 3200 meters,

and the far-field photon counting at $90 \mathrm{~m}$ resolution above 3200 meters)

All data post ozone profile extraction smothed using 5-point least squares

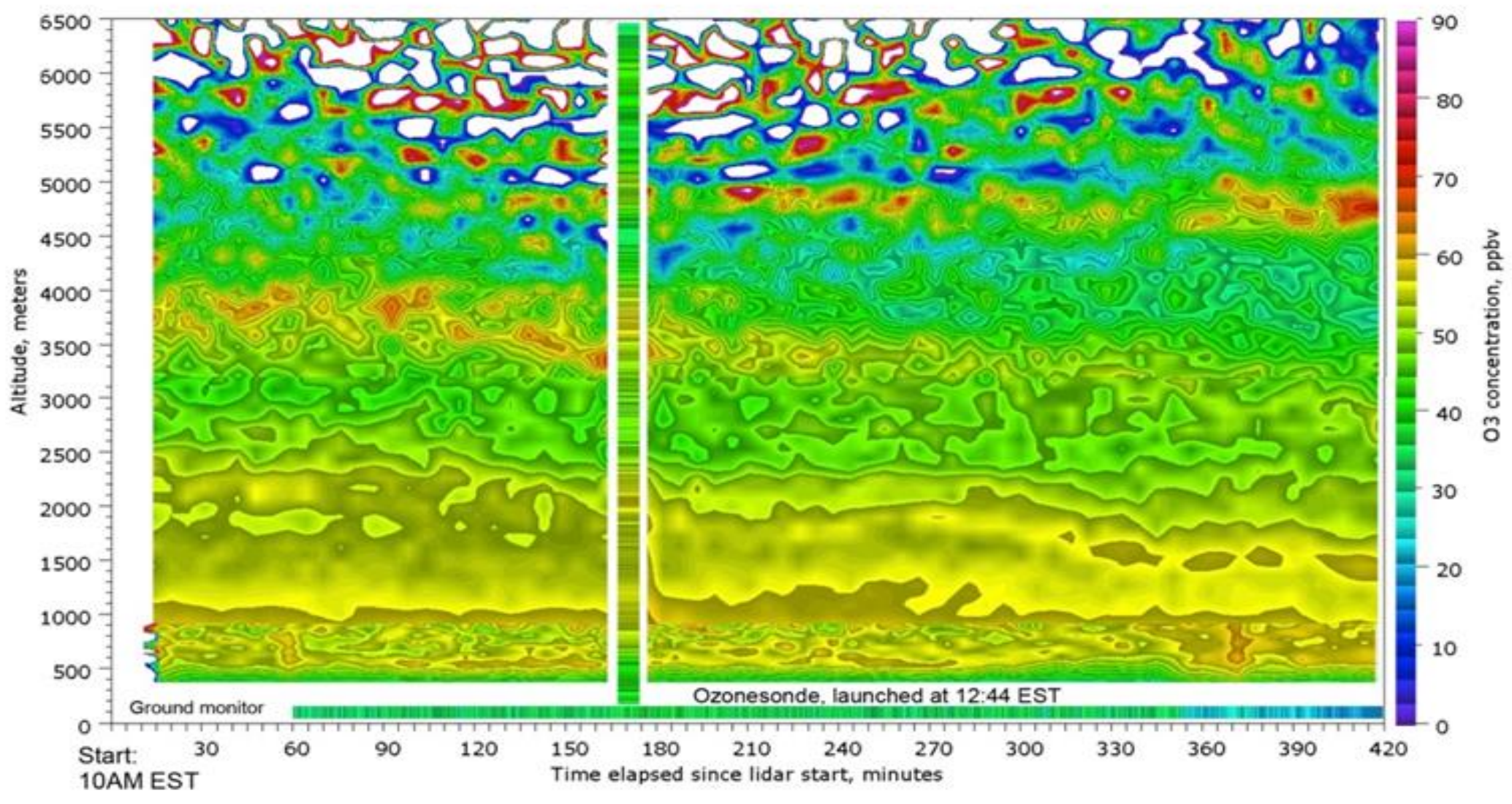




\section{DISCOVER-AQ Golden, CO Ozone and Aerosol Profiles Aug. 11, 2014}

(top) LMOL analog channel, $90 \mathrm{~meter} \times 10 \mathrm{~min}$ res.. 5 -pt $5 \mathrm{~mol}$ - $10 \mathrm{ing}$ (bottom) $527 \mathrm{~nm}$ attenuated backscatter, 3 meter $\times 20$ sec resolution

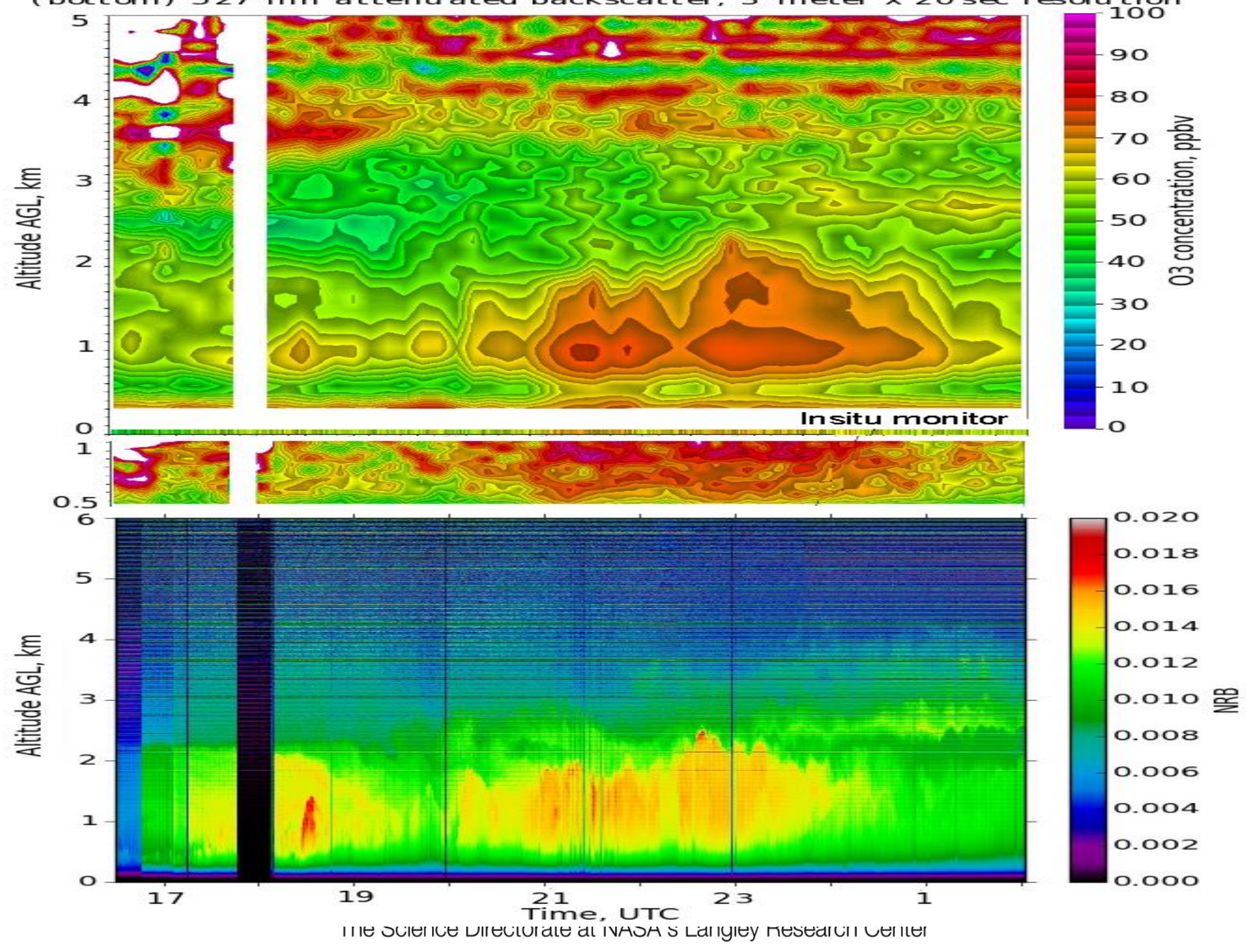




\section{DISCOVER-AQ Stratospheric Intrusion Golden, CO Aug 6, 2014}

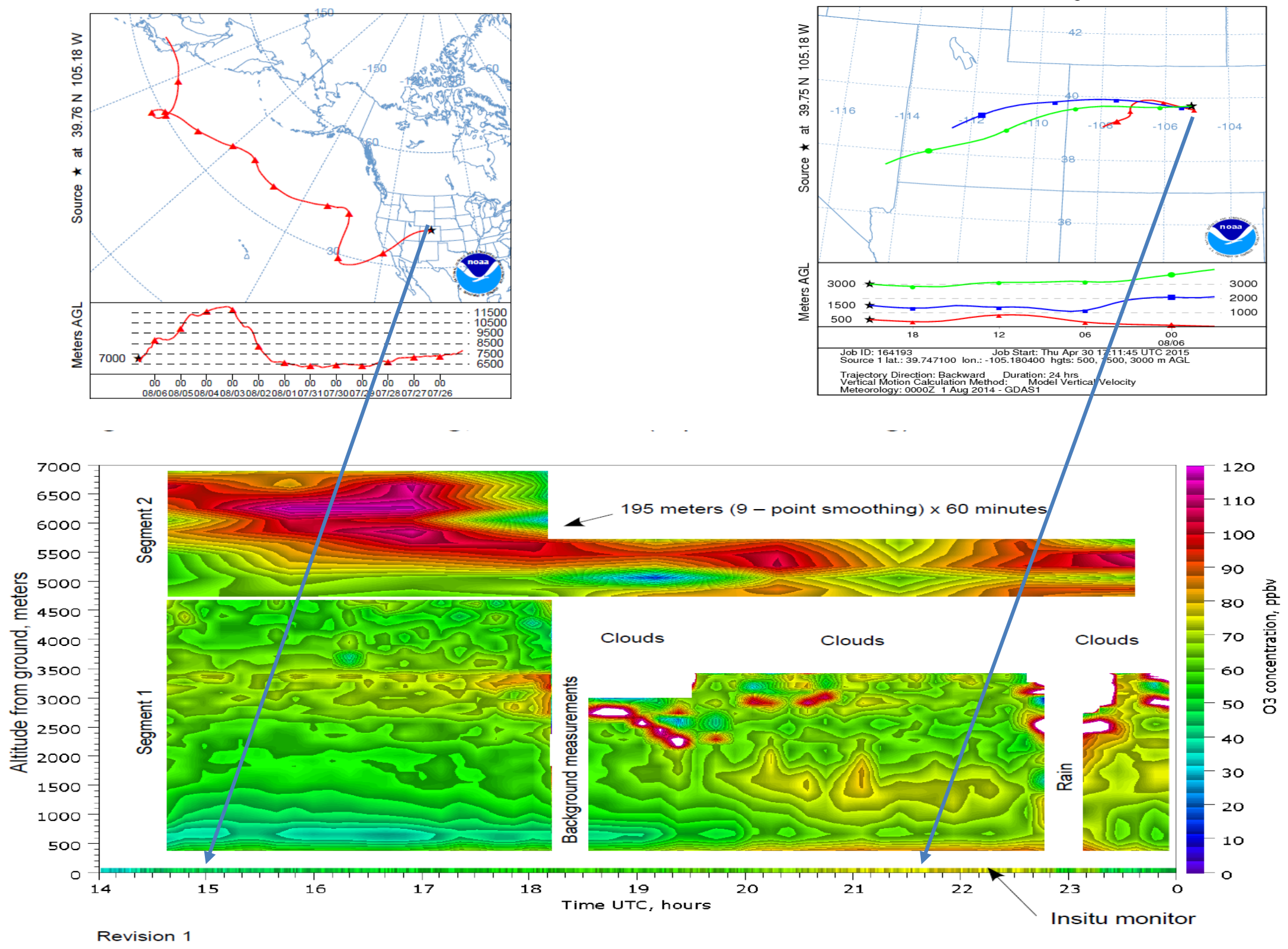


July 28, 2014 - L-MOL Analog profile: 90 meters (5-point smoothing) $\times 10$ minutes resolution Photon counting profile: 112.5 meters (9-point smoothing) $\times 10$ minutes resolution Very near field: 30 meters (5-point smoothing $\times 10$ minutes resolution) Location: Golden, CO (Lat: 39.755742, Lon: -105.184479), Altitude: 1842 m

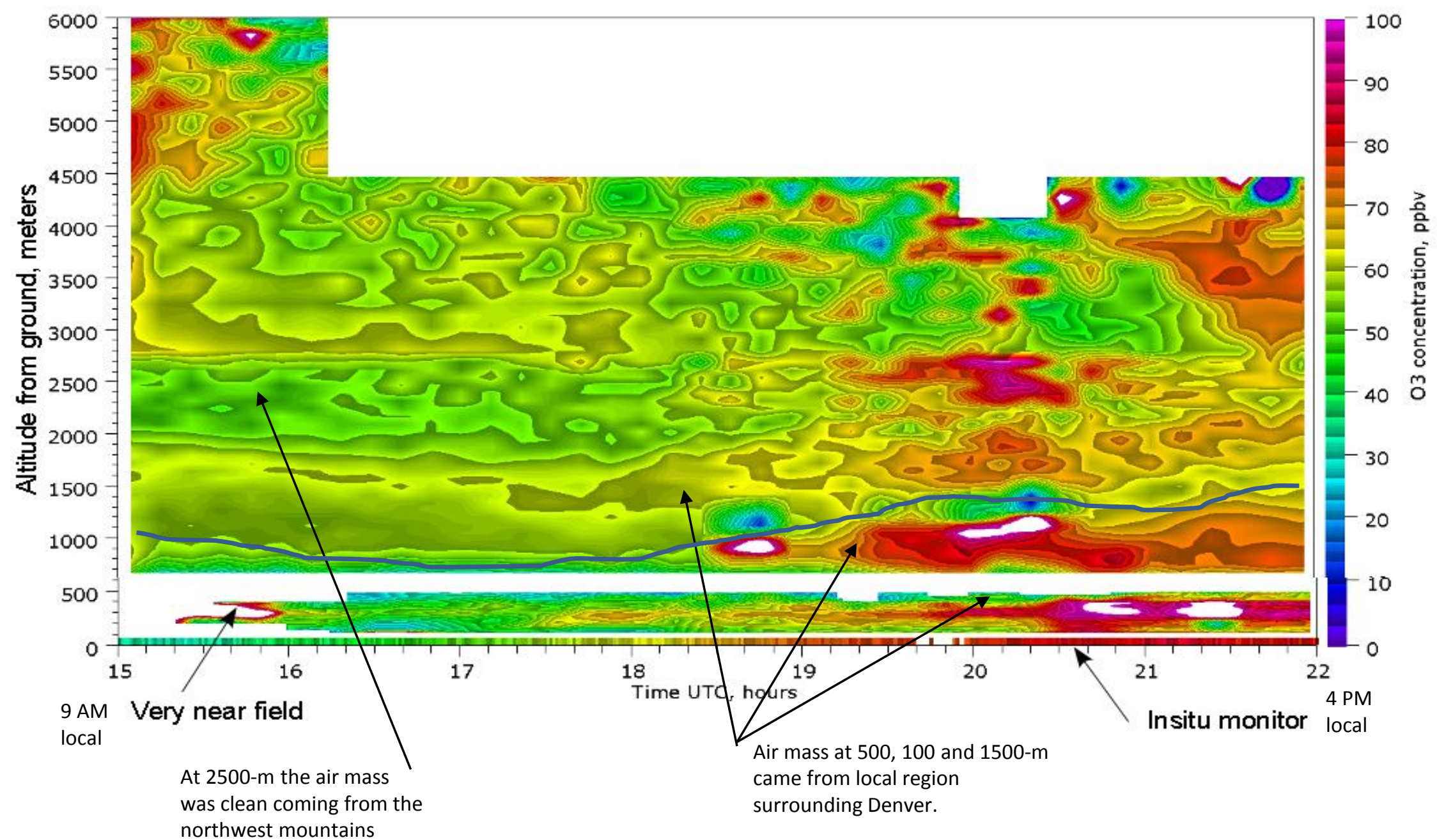


August 29, 2014 Table Mountain , Golden, Colorado Ozone and

\section{Aerosol Scattering Ratio Profiles}

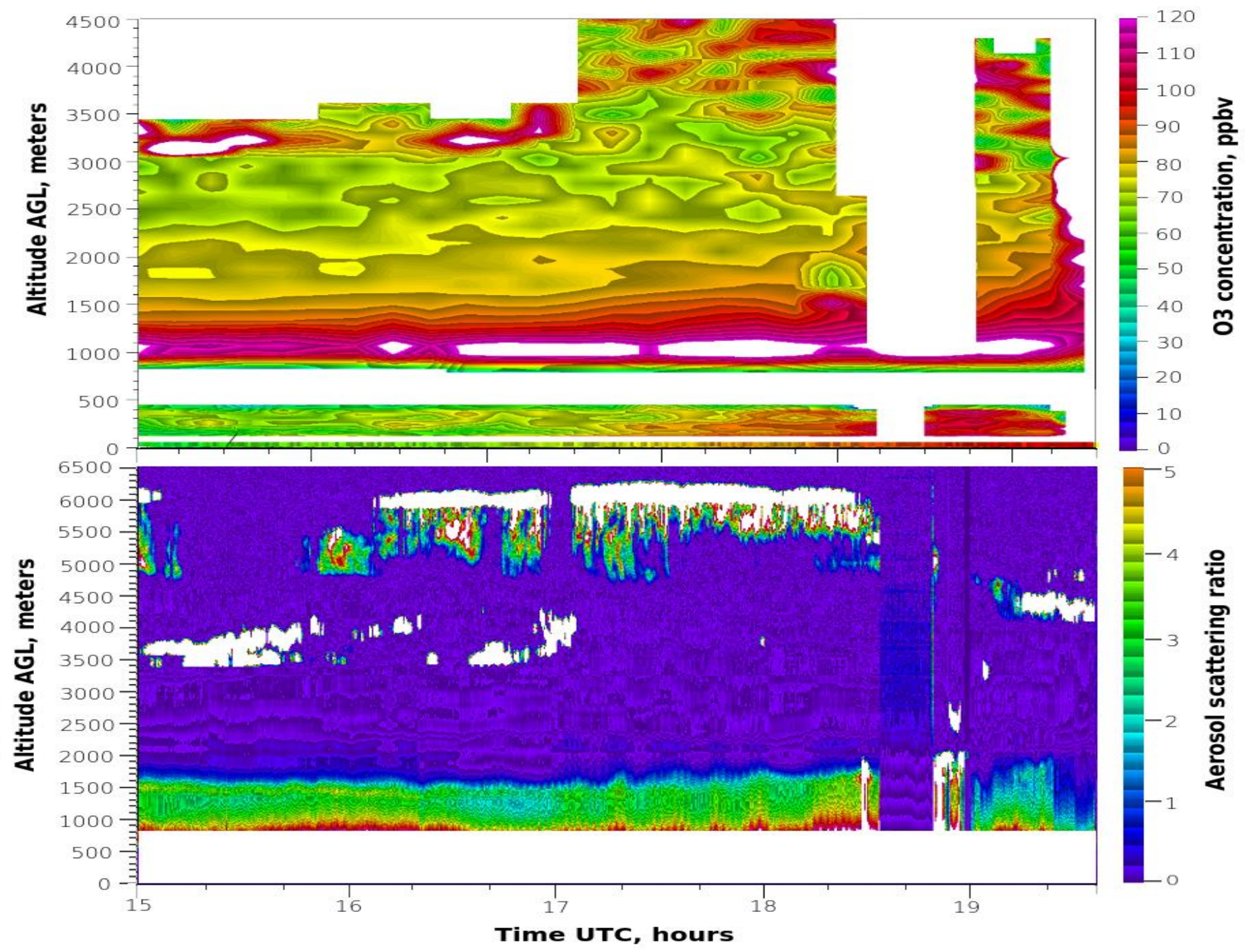


July 29, 2014 - L-MOL Analog profile: 90 meters (5-point smoothing) $\times 10$ minutes resolution Photon counting profile: 112.5 meters (9-point smoothing) $\times 10$ minutes resolution

Very near field: 36 meters (5-point smoothing) $\times 10$ minutes resolution

Location: Golden, CO (Lat: 39.755742, Lon: -105.184479), Altitude: $1842 \mathrm{~m}$

The spirals show the airplane sampling projections ( spiral diameter $4-9 \mathrm{~km}$ )
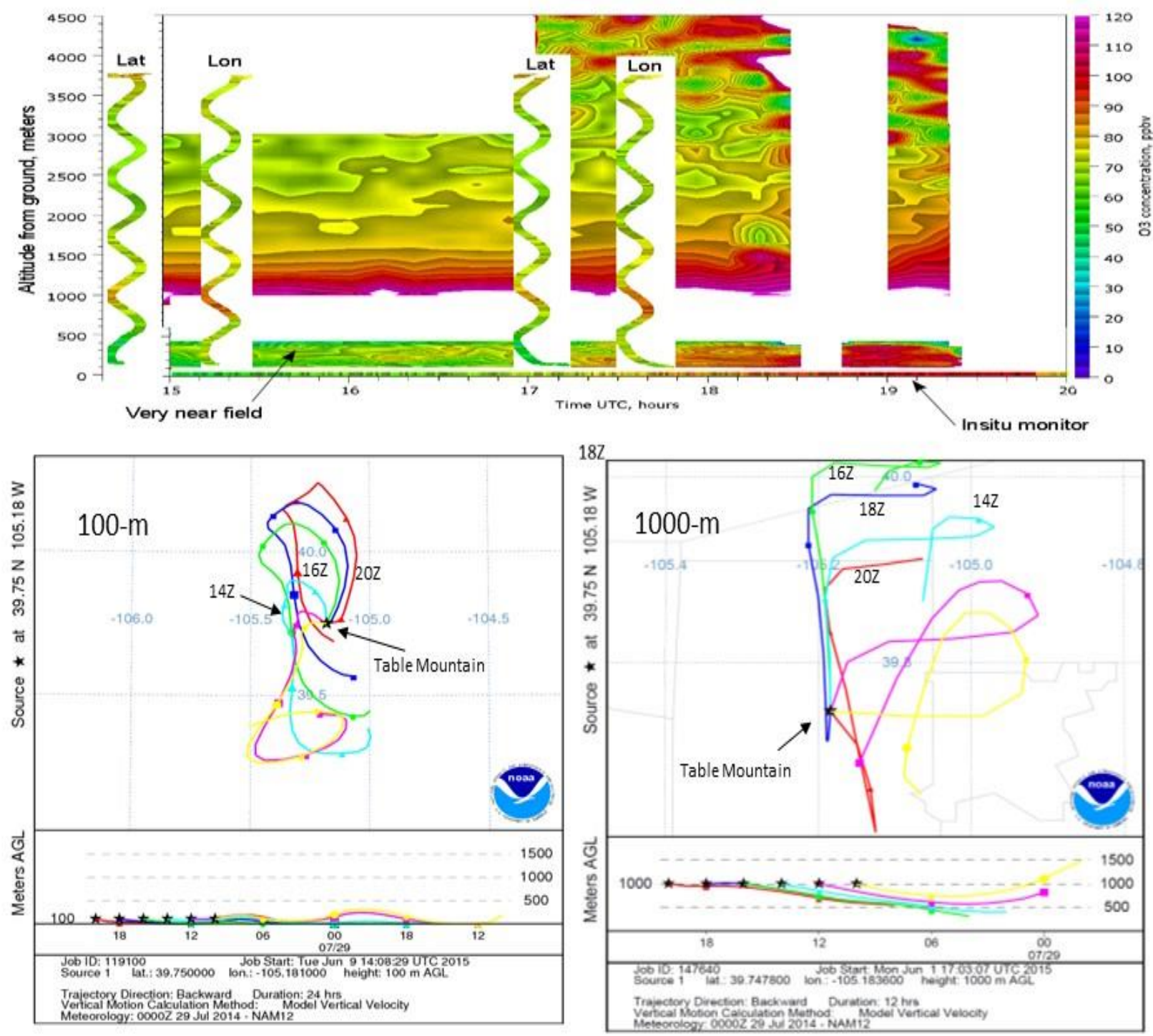
August 11, 2014 - L-MOL Analog profile: 90 meters (5-point smoothing) $\times 10$ minutes resolution Near field: 60 meters (5-point smoothing) $\times 10$ minutes resolution Location: Golden, CO (Lat: 39.755742, Lon: -105.184479), Altitude: $1842 \mathrm{~m}$

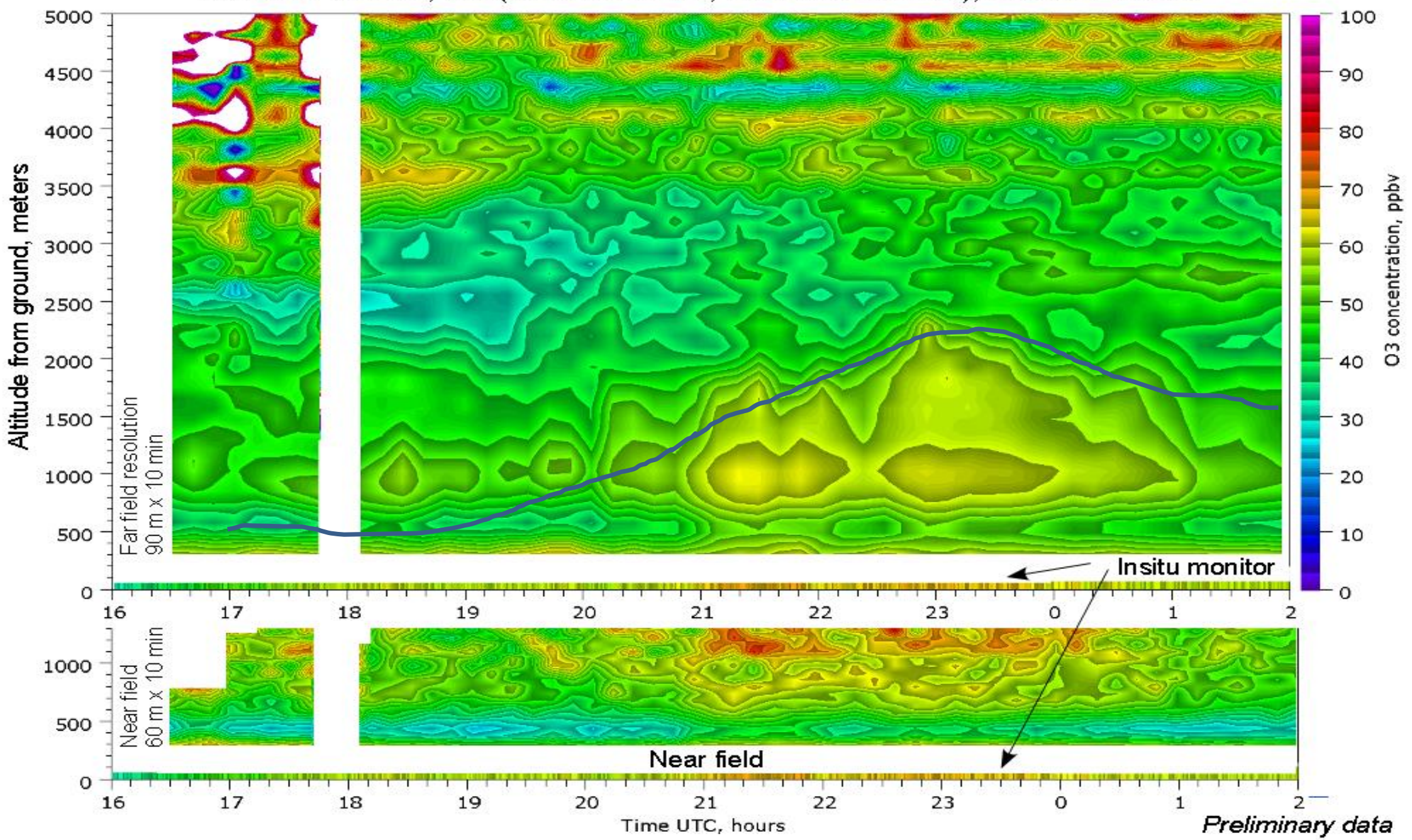




\section{Peak Ozone Lidar Trends from South Table Mountain, Golden, CO}

(July 16, 17 at Boulder Atmospheric Observatory, Erie, CO)

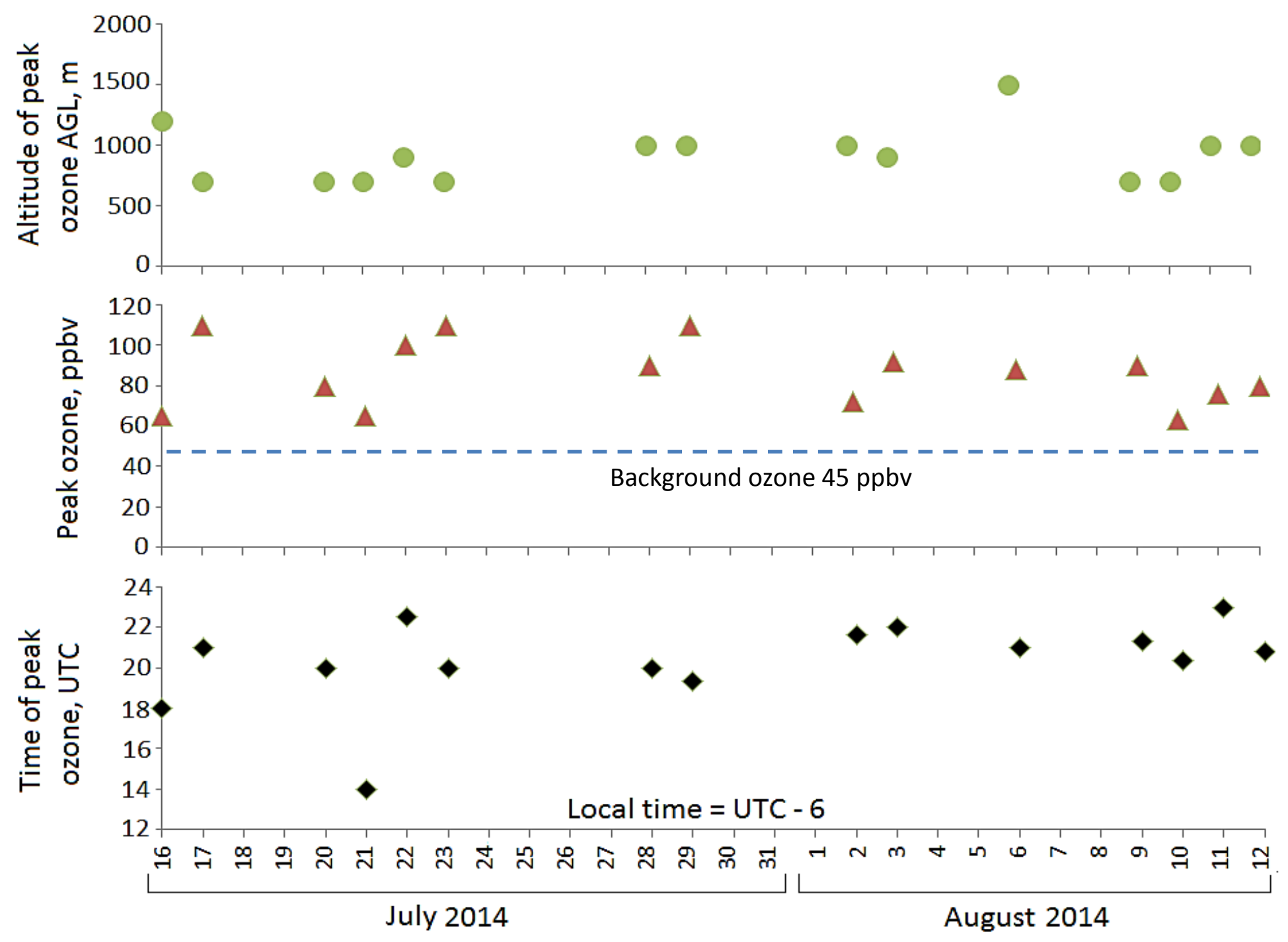




\section{Conclusions}

- LMOL validated by many ozonesonde comparisons within $\sim 5 \%$ of sonde.

- Participated in DISCOVER-AQ Denver campaign summer 2014.

- Ozone and aerosol (527 nm) profiles from ground (2B in-situ) to $\sim 4-\mathrm{km}$.

- Current research with Virginia Dept. of Environmental Quality and Colorado Air Pollution Control Division. 


\section{Langley Mobile Ground-based Lidar Ozone Profiling}
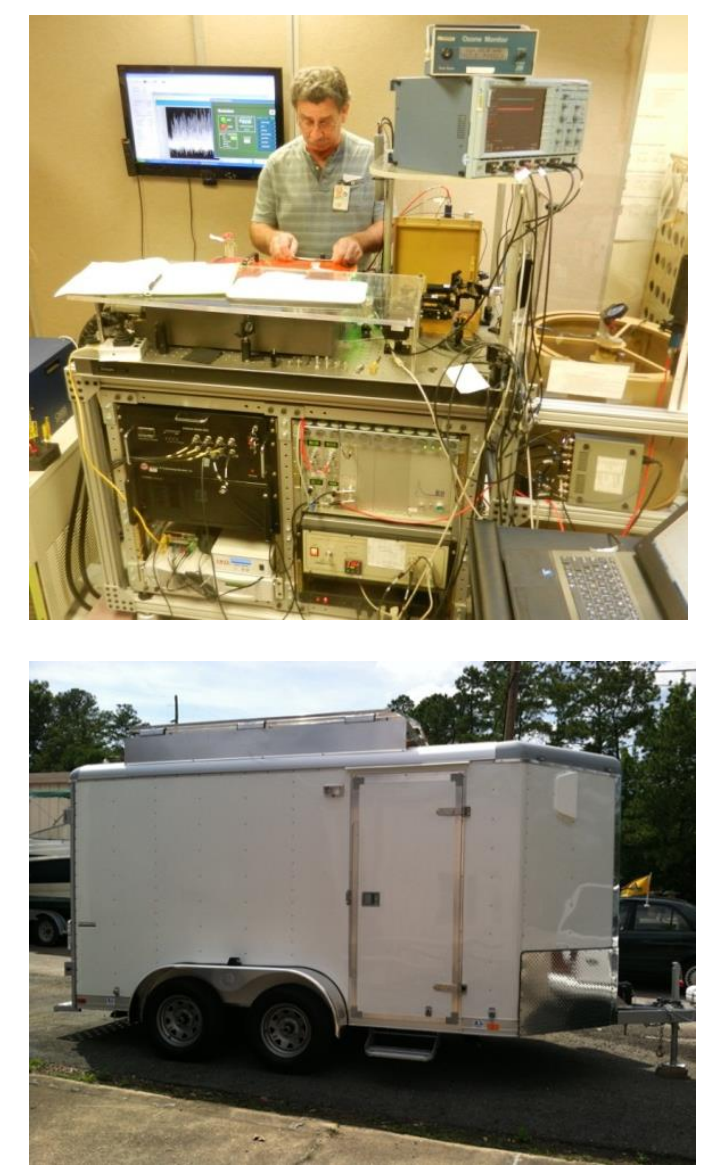

Mobile ozone is operational in trailer. New analog data system near operational. Will be deployed in DISCOVERT-AQ Denver July15-August 15, 2014.
Russell De Young

Langley Research Center

\section{Ozone Lidar Operation Schematic}

Operational ozone lidar taking weekly atmospheric profiles with ozonesonde launch

Operational lidar in Langley lab

Four Channel Lidar

- In-situ ozone 4 m

- Far Field ozone 4-7 km

- Near field ozone 1.5-4 km

- Very near field ozone .1-1.5 km

- Green aerosol 1-10 km

Hampton Roads Ozone Profile: Example of Ozone

Lidar to be deployed in trailer

Sept. ozone curtain plot showing ozone transport from DC above boundary layer with local ozone below boundary layer
Transport and Local Ozone Generation

Orone prefile, Sept 24, 2013
Mhoton courting at abitudes above 1500 meters and an

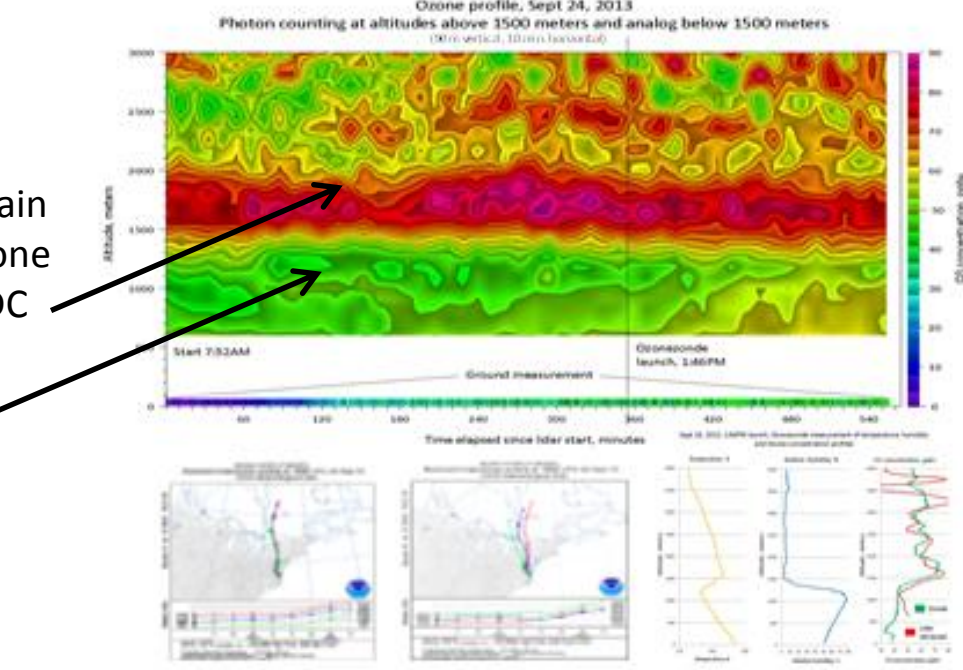




\section{Receiver Detector Module}

- The receiver box contains optics which direct the transmitted light from the fiber optic cable into the APD and two UV PMT detectors.

- The APD is used for collection of the visible return signal.

- One PMT is used for near-field UV detection.

- The other PMT is used as a farfield UV detector for a Licel Transient Recorder that can

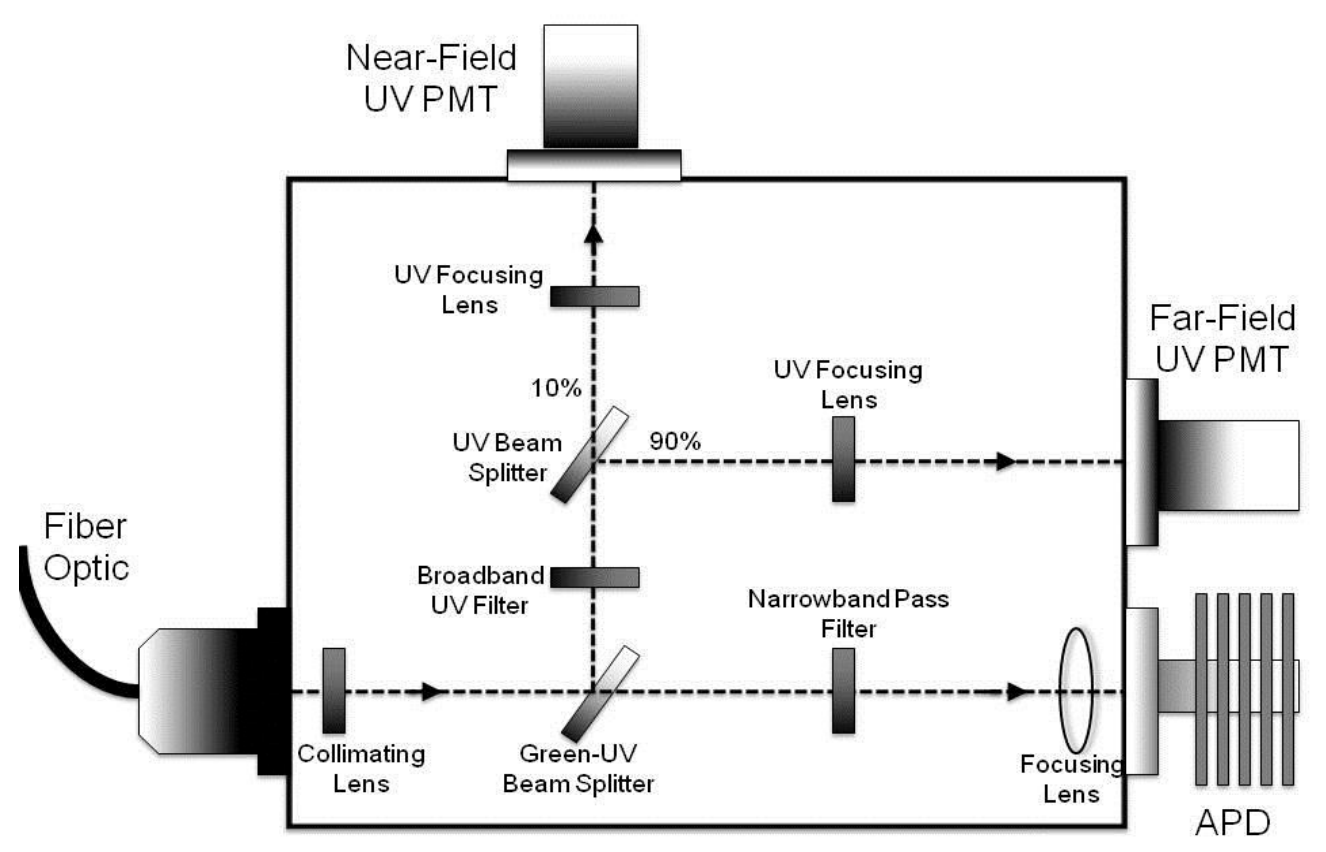
acquire both analog and photon counting signals. 


\section{Science Investigations Addressed by the Mobile Ozone Lidar System}

- Provide high spatio-temporal profiles of Planetary Boundary Layer (PBL) and Free Troposphere (FT) ozone and aerosols to study the atmospheric structure that GEO-CAPE will observe and assess the fidelity with which a geo instrument can measure that structure.

- Discover new structures and processes at the PBL/FT boundary, especially in the diurnal variation of that interface.

- Help improve air-quality forecast models. Field an ozone lidar that would be suitable to populate a network to address the needs of NASA/EPA/NOAA air-quality scientists and managers who increasingly express a desire for ozone profiles.

- Participate in Denver DISCOVER AQ campaign July-August 2014.

- Improve understanding of ozone and aerosols aloft and surface ozone and PM values. Advance our understanding of processes controlling regional background atmospheric composition and their effect on surface air quality to prepare for the GEO-CAPE era. 


\section{8-hour Design Value Projections to 2020}

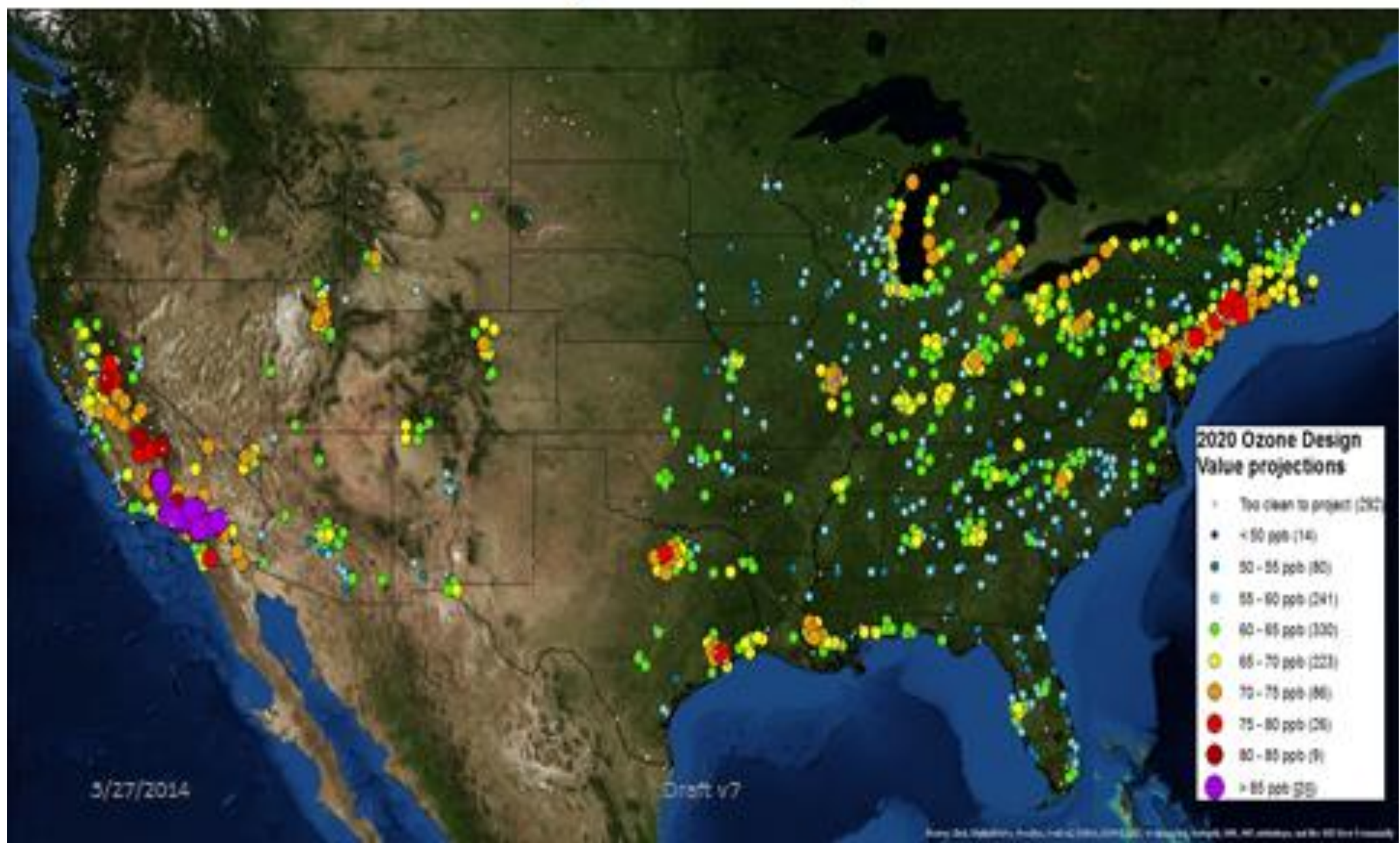




\section{Hampton Roads Ozone Profile: Example of Ozone Transport and Local Ozone Generation}

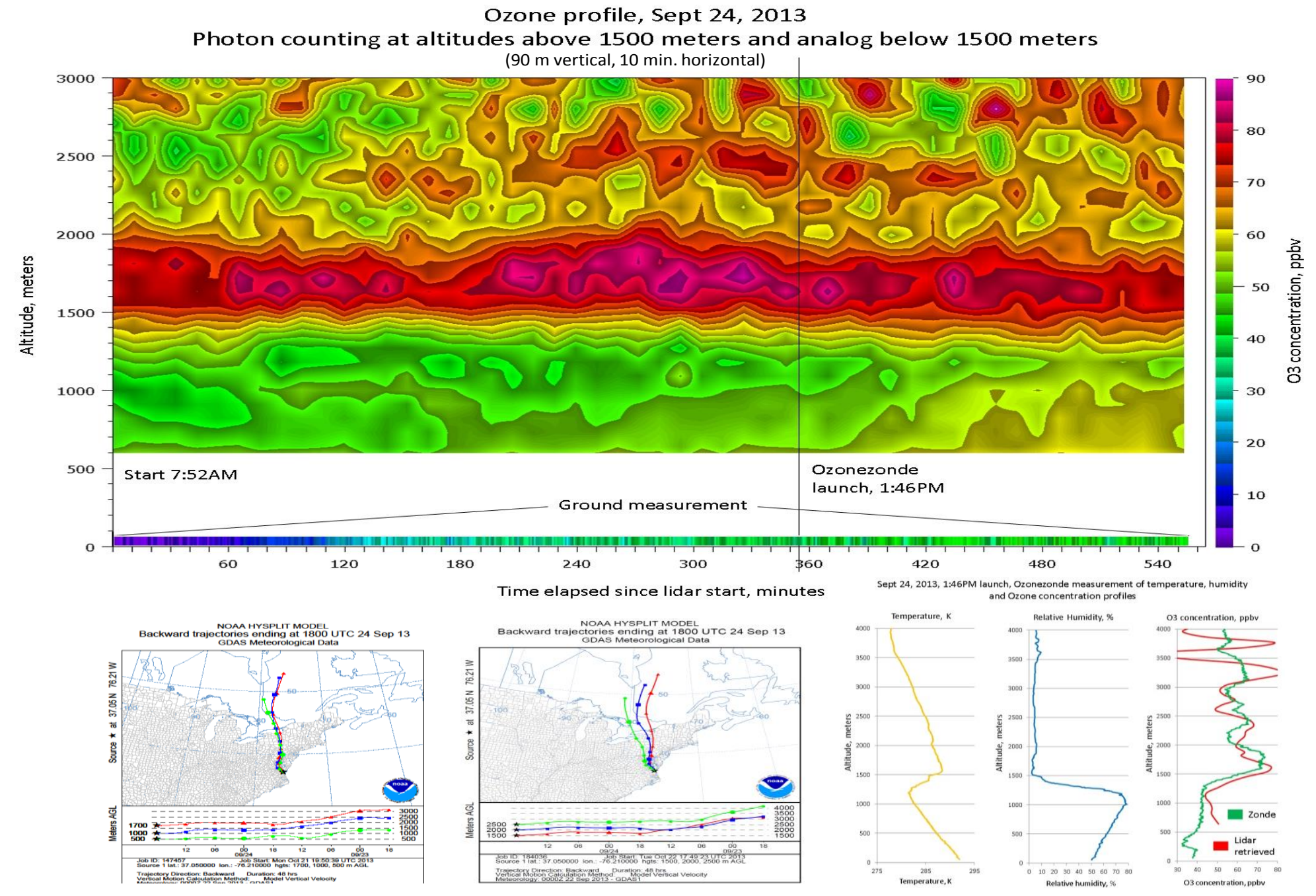




\section{Hampton Roads Ozone Profile: Example of Low Ozone Generation with Little Transport}

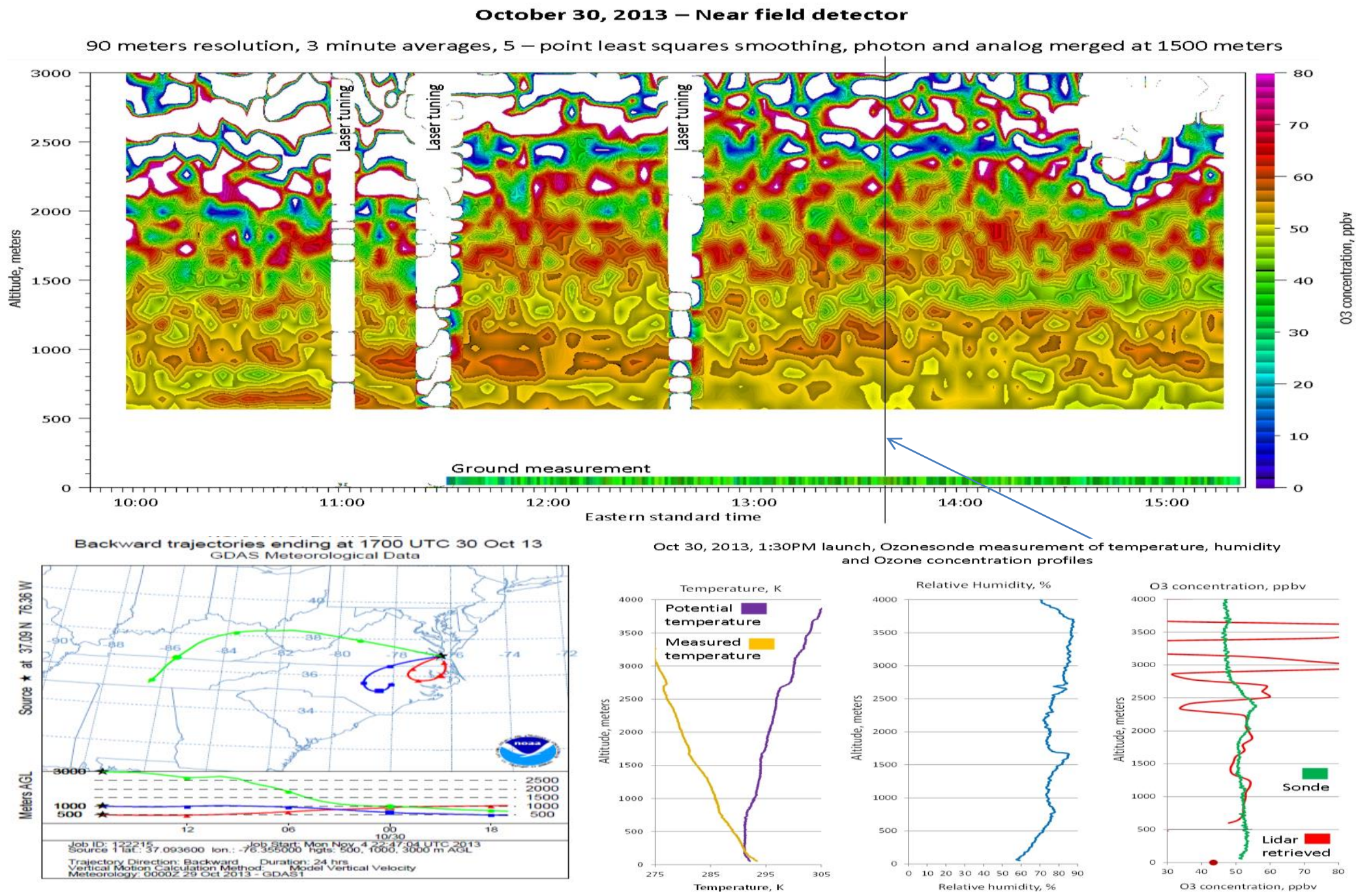


May 4 (12:00 AM through 3:20 PM). Combined curtain plot (analog below $3000 \mathrm{~m}$, photon counting above $3000 \mathrm{~m}$ ),

Analog: $10 \mathrm{~min} \times 90 \mathrm{~m}$ resolution with 5 -point least squares smoothing, and Photon coutning: $112.5 \mathrm{~m}$ with 9-point least squares smoothing of the final ozone profile. Sonde launched at 2:46AM used in ozone concentration profile extraction. The plot spans over 15 hours and combines 2664 Licel files, online $=287.09 \mathrm{~nm}$, offline $=292.7 \mathrm{~nm}$, diff. cross-section of $2.677 \mathrm{e}-23 \mathrm{~m}^{\mathrm{A}} 2$.

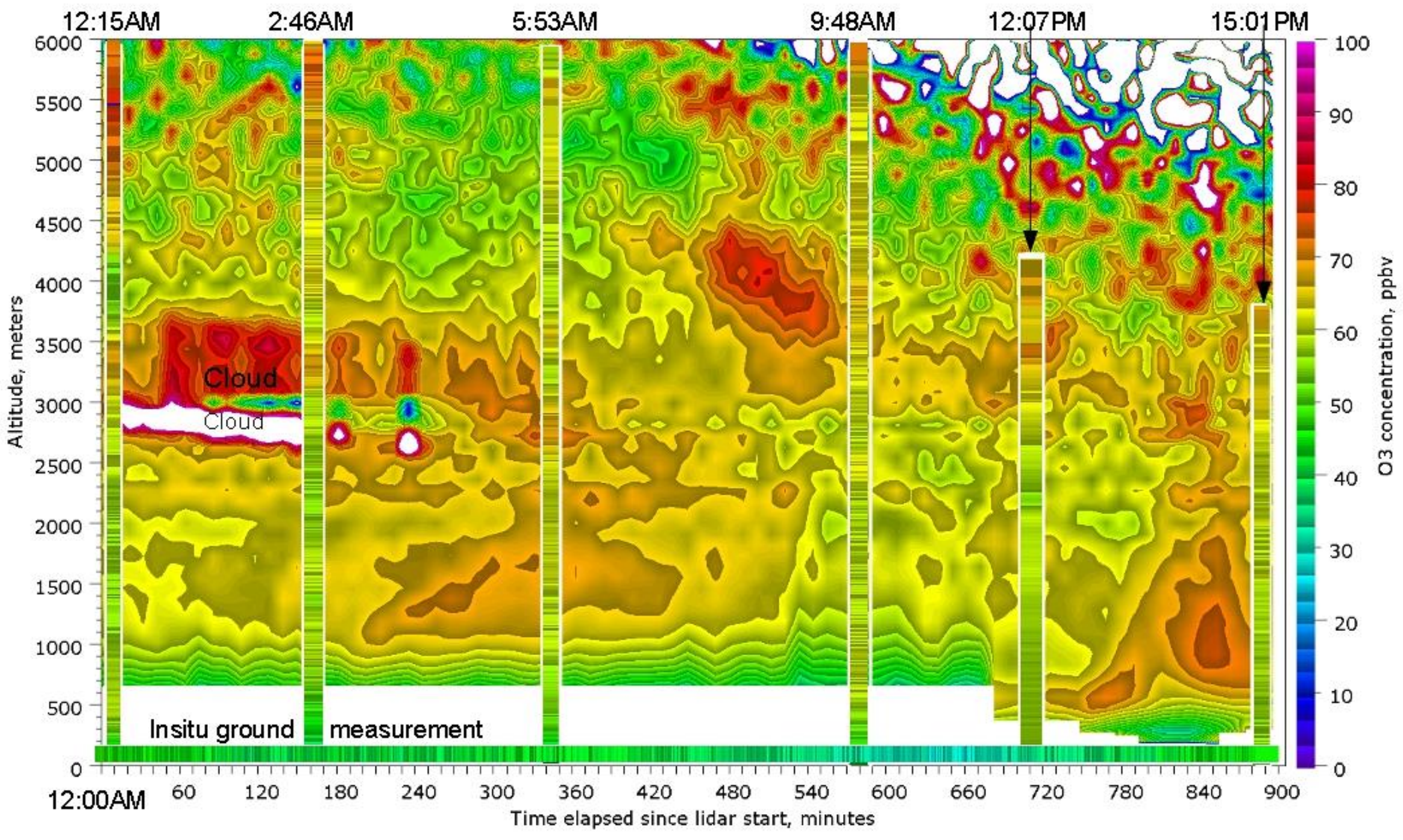




\section{Optical Schematic of Pump Laser and Tunable UV Laser}

Nd:YLF diode pumped laser with intra-cavity frequency doubling (Coherent Evolution 30 TEM $_{00}$ )

Ce:LiCAF tunable UV laser. Green $527 \mathrm{~nm}$ is the second harmonic output beam from the Nd:YLF laser. Fourth harmonic $263 \mathrm{~nm}$ output, generated in CLBO crystal, is split into two beams then focused on the Ce:LiCAF crystal. Oscillating mirror cavity generates tunable 280-300nm output.

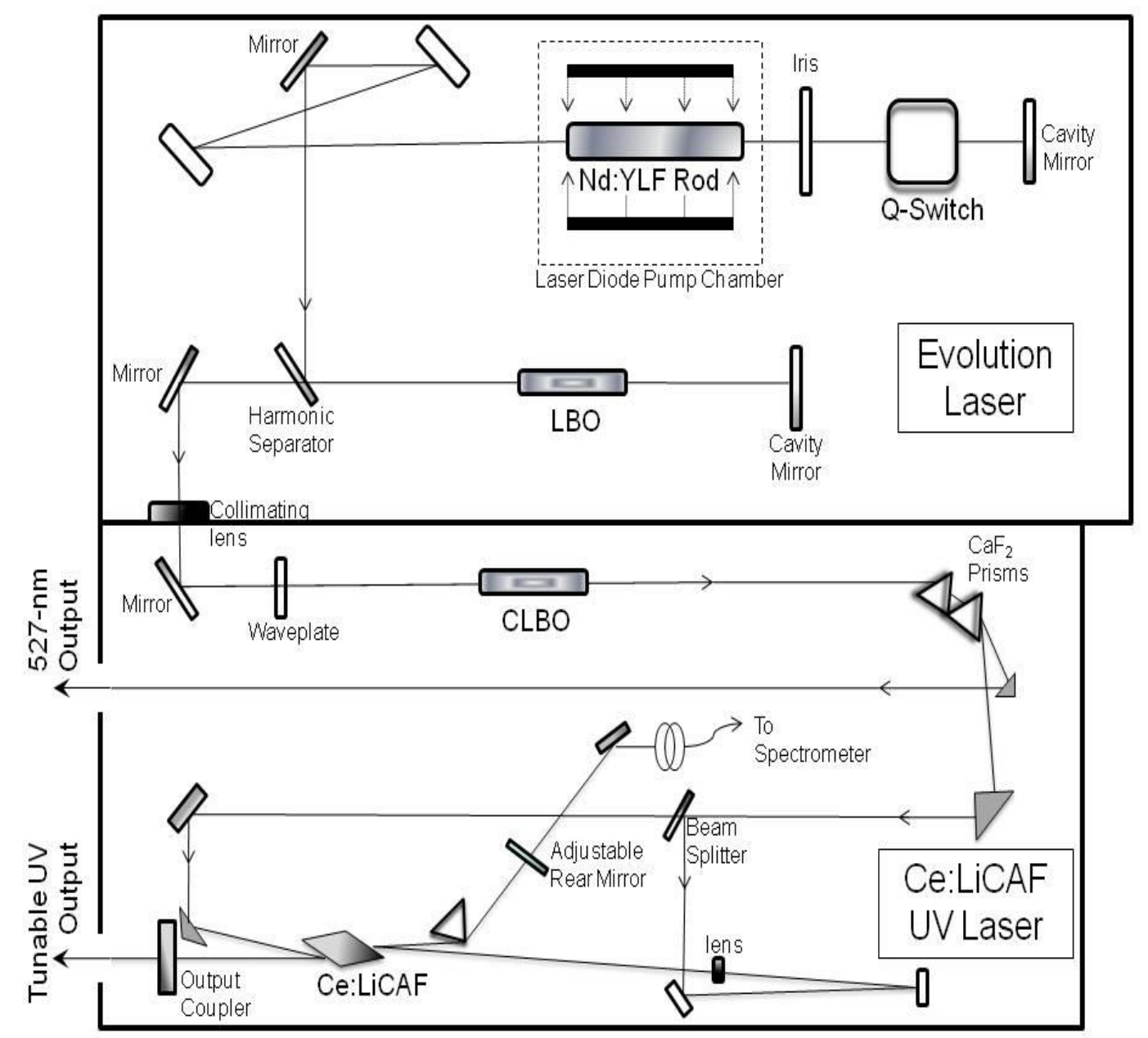




\section{Laser Transmitter Conversion Steps}

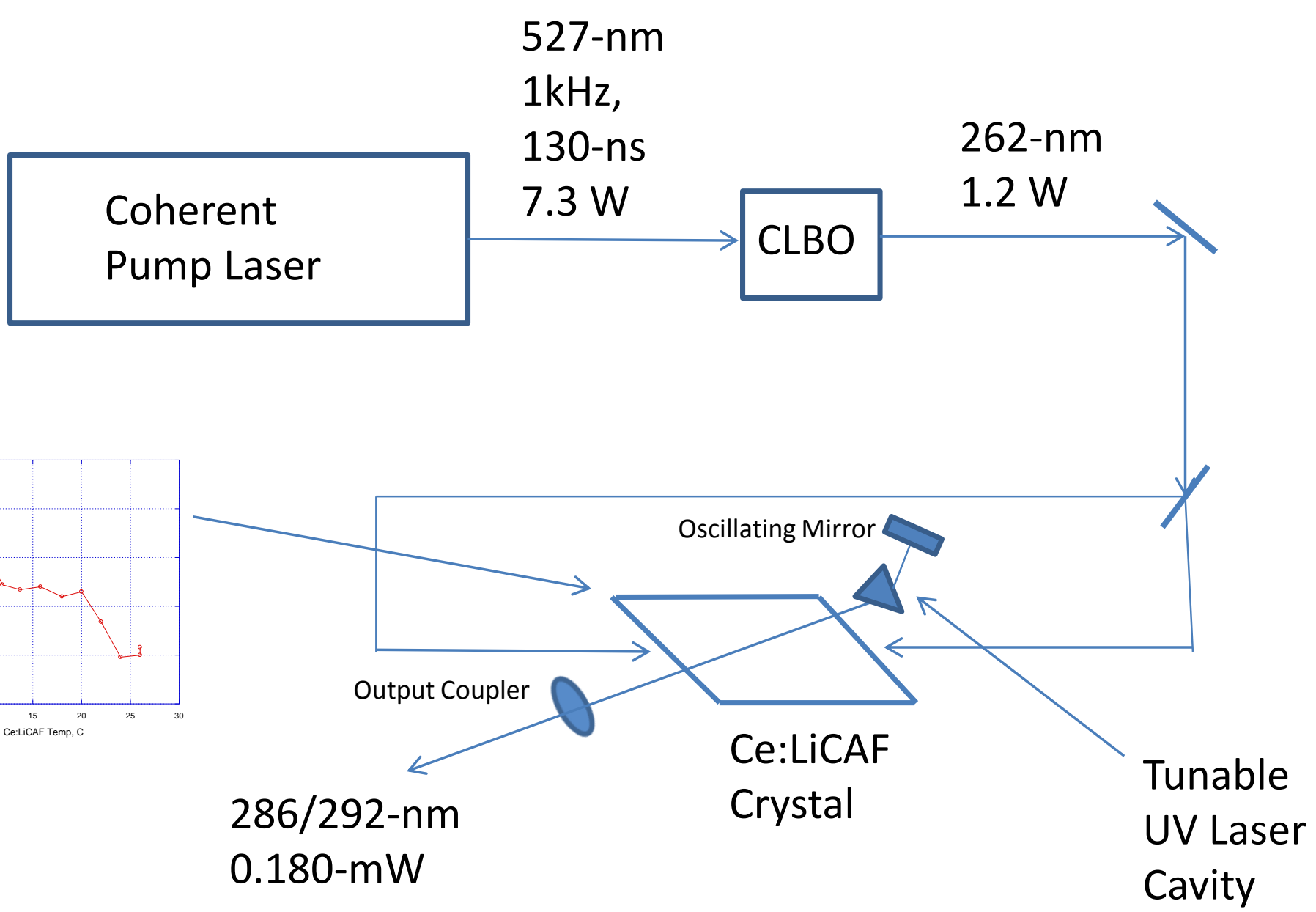


Solar Actinic Flux and Ozone Absorption Cross-section vs Wavelength

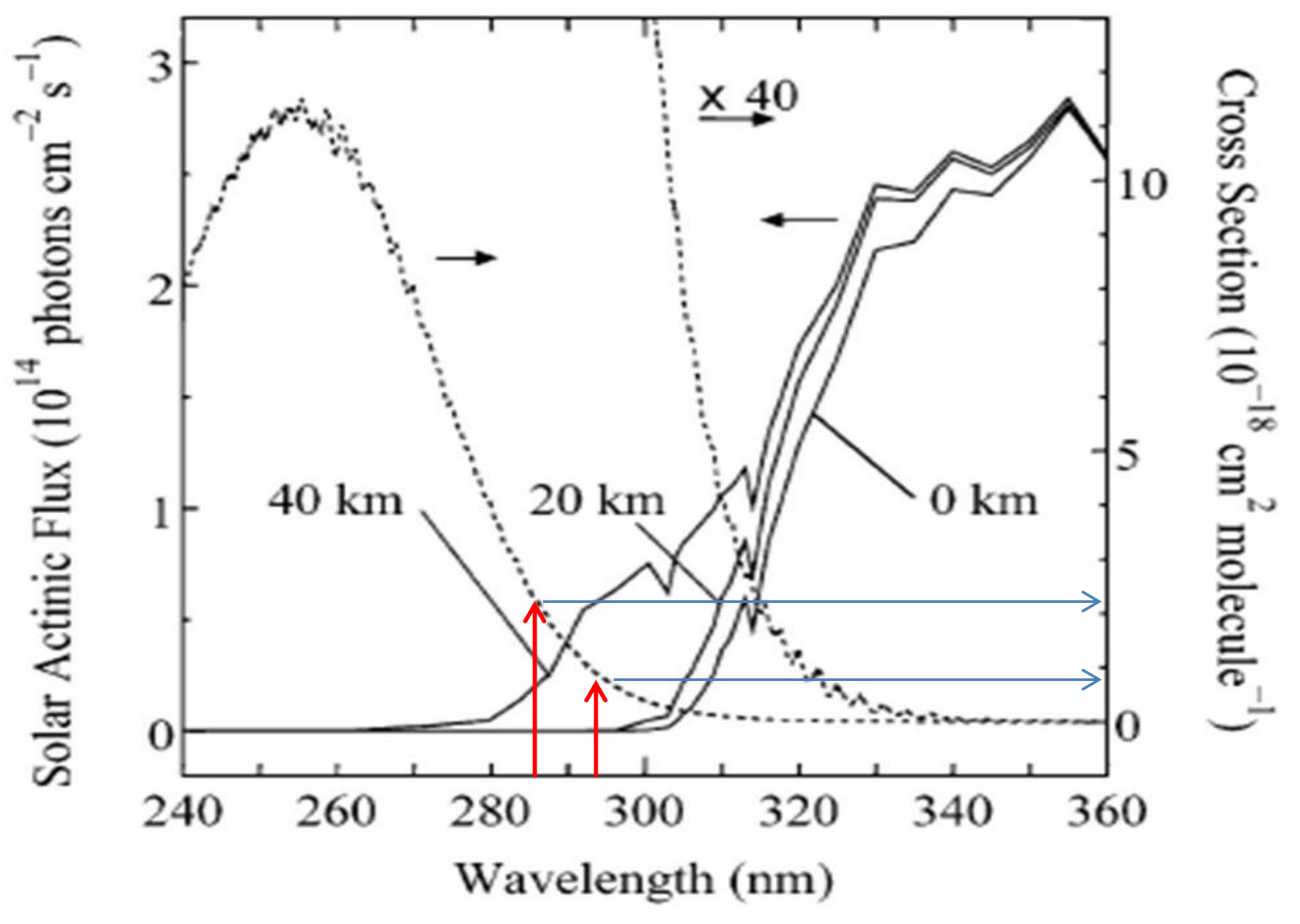

Matsumim and Kawasaki, Chem.Rev., 103, 2003 


\section{Analog (red) and Photon Counting (Green) Ozone Compared to Ozonesonde (black)}

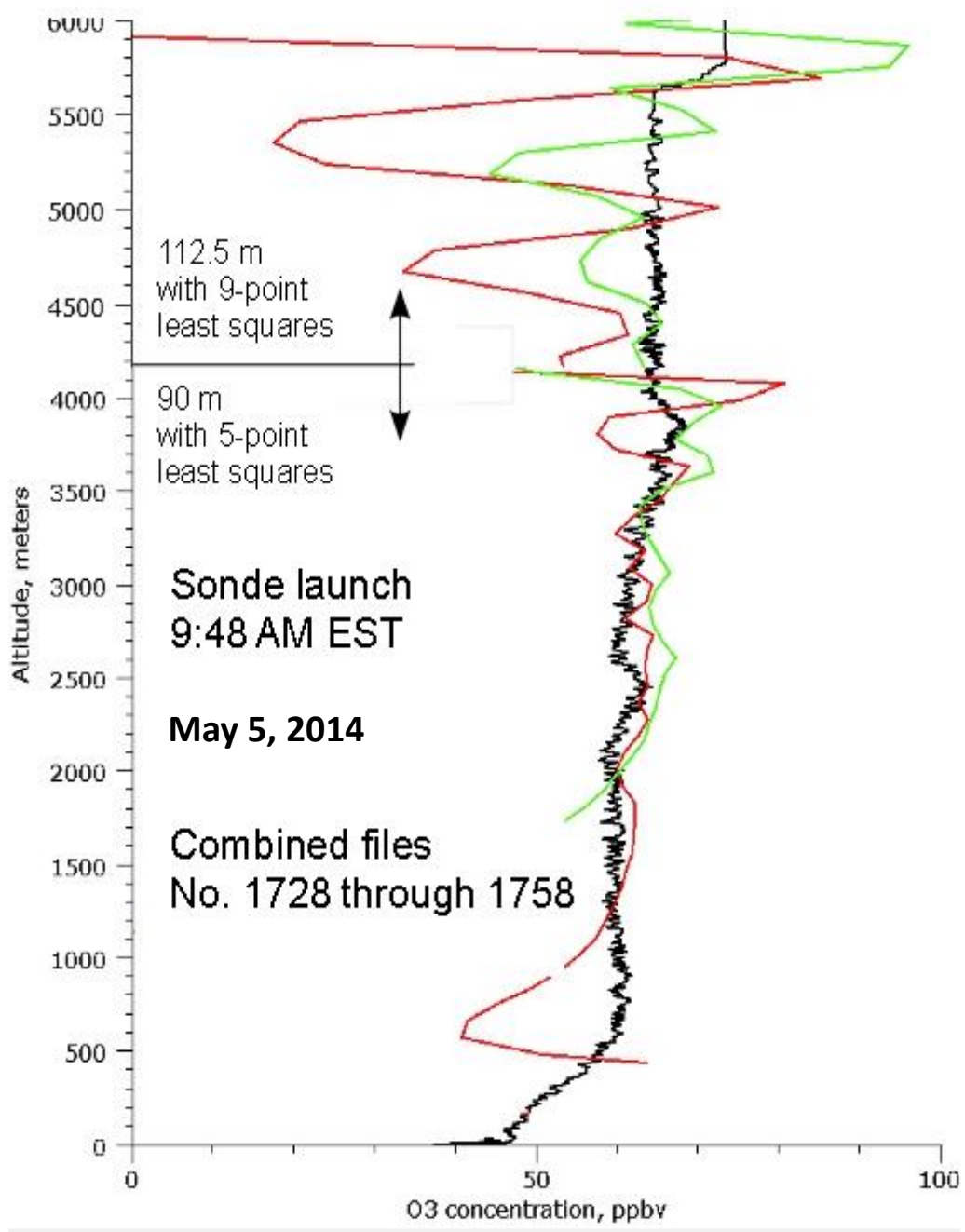




\section{Ozone Lidar Specifications}

\begin{tabular}{|c|c|}
\hline \multicolumn{2}{|c|}{ PUMP LASER } \\
\hline Green output of Nd:YLF laser & $12 \mathrm{~mJ} /$ pulse, $527 \mathrm{~nm}$ (max) \\
\hline UV output for pumping Ce:LiCAF laser & $2.8 \mathrm{~mJ} /$ pulse, $263 \mathrm{~nm}(\max )$ \\
\hline Repetition rate & $1 \mathrm{kHz}$ \\
\hline \multicolumn{2}{|c|}{ LIDAR TRANSMITTER } \\
\hline Ce:LiCAF laser energy & $0.1 \mathrm{~mJ} /$ pulse \\
\hline Wavelength tuning range & $285-300 \mathrm{~nm}$ \\
\hline Typical ozone wavelengths & 285.7 and $291.4 \mathrm{~nm}, 500 \mathrm{~Hz}$ each \\
\hline Laser line width & $\sim 0.2 \mathrm{~nm}$ \\
\hline Laser beam diameter, divergence & $\sim 0.8 \mathrm{~cm}$ and $0.13 \mathrm{mrad}$ \\
\hline Transmitted green, divergence & $2 \mathrm{~mJ} /$ pulse, $527 \mathrm{~nm} ; 0.85 \mathrm{mrad}$ \\
\hline \multicolumn{2}{|c|}{ LIDAR RECEIVER } \\
\hline Near Field Telescope & $40 \mathrm{~cm}$ dia. Newtonian (62\% efficiency) \\
\hline Fused silica optical fiber & $1 \mathrm{~mm}$ dia., $\mathrm{NA}=0.28$ \\
\hline Field of view & $1.4 \mathrm{mrad}$ \\
\hline UV channel, $\lambda_{\mathrm{c}} 285-300 \mathrm{~nm}, \mathrm{~T}=60 \%$ & PMT - analog + photon counting \\
\hline Green channel $, \lambda_{\mathrm{c}} 527 \mathrm{~nm}, \Delta \lambda=0.3 \mathrm{~nm}, \mathrm{~T}=43 \%$ & PMT - analog \\
\hline Very near field telescope & $30 \mathrm{~cm}$ dia. Fresnel telescope \\
\hline \multicolumn{2}{|c|}{ POWER REQUIREMENTS } \\
\hline Laser + control system & $1 \mathrm{KW}$ \\
\hline Chiller & $1 \mathrm{~kW}$ \\
\hline
\end{tabular}

